6. Зимин Л.С. Сем. Muscidae. Настоящие мухи (трибы Muscini, Stomoxydini) // Фауна СССР. Насекомые двукрылые. Т. XVIII. Вып. 4. М.-Л.: Изд-во АН СССР, $1951.286 \mathrm{c}$.

7. Catalogue of Palaearctic Diptera. Vol. 11. Scathophagidae - Hypodermatidae. Budapest, 1986. 346 p.

8. Административная карта «Самарская область», масштаб 1:500 000. М.: Роскартография, 1997.

9. Любвина И.В. Таксономический состав двукрылых (Brachycera, Diptera) антропогенных биотопов Caмарской Луки // Принципы и способы сохранения биоразнообразия: Сб. матер. Всерос. науч. конф. (18-24 сентября 2004 г.). Йошкар-Ола, 2004. С. 101-102.

10. Любвина И.В. Двукрылые (Diptera, Brachycera) каменистых степей Самарской Луки // Известия Самарского научного центра РАН. Спец. выпуск «Природное наследие России». Ч. 2. 2004. С. 358-363.

11. Любвина И.В. Отряд Diptera (Двукрылые) // Кадастр беспозвоночных животных Самарской Луки: учебное пособие. Самара, 2007. С. 287-322.

12. Любвина И.В. Двукрылые (Diptera, Brachycera) пойменных биотопов Самарской Луки // Актуальные вопросы энтомологии: материалы II Междунар. науч.практ. интернет-конференции (г. Ставрополь, 1 марта 2009 г.). Вып. 5. Ставрополь: АГРУС, 2009. С. 69-72.

13. Любвина И.В. Двукрылые (Diptera) Рачейского и Муранского боров Самарской области // Вестник Волжского ун-та им. В.Н. Татищева. Серия «Экология». Вып. 12. Тольятти, 2011. С. 63-67.

14. Любвина И.В. Двукрылые (Diptera, Brachycera) Самарской Луки. Эколого-фаунистическая характери- стика: LAP LAMBERT Academic Publishing, 2012. $200 \mathrm{c}$.

15. Любвина И.В. Короткоусые двукрылые (Diptera Brachycera) остепненных биотопов Самарской области // Степи Северной Евразии: материалы VII международного симпозиума / под науч. ред. чл.-корр. РАН А.А. Чибилёва. Оренбург: ИС УрО РАН, Печатный дом «Димур», 2015. С. 490-492.

16. Животный мир Среднего Поволжья (полезные и вредные животные). 2-е доп. и испр. изд. / под ред. проф. П.А. Положенцева и Я.Х. Вебера. Куйбышев: ОГИЗ, Куйбышевское идз-во, 1941. 303 с.

17. Халидов А.Б., Краснобаев Ю.П. О двукрылых насекомых макромицетов Жигулёвского заповедника // Проблемы кадастра, экологии и охраны животного мира России: Тез. Всерос. конф. (15-19 октября 1990 г.). Воронеж, 1990. С. 11-12.

18. Прохорова Н.В., Сачков С.А., Виноградов А.В. Изучение Жигулёвской городской свалки и её рекультивация // Самарская Лука. Бюллетень. 1999. № 9/10. C. $301-317$.

19. Ковригина А.М. Беспозвоночные животные г. Самары // Краеведческие записки. Вып. XIII. Самара, 2004. С. $77-87$.

20. Любвина И.В. Изучение семейств двукрылых (Diptera, Brachycera Cyclorrhapha) Самарской области // Самарский край в истории России. Вып. 5. Материалы межрегиональной научной конференции, посвященной 190-летию со дня рождения П.В. Алабина. Самара, 2015. C. 66-70.

\title{
ON THE FAUNA OF HOUSE FLIES (DIPTERA, MUSCIDAE) OF SAMARA REGION
}

(C) 2016

I.V. Lyubvina, candidate of biological sciences, senior researcher I.I. Sprygin Zhiguli State Nature Biosphere Reserve, Zhigulyovsk (Russia)

Abstract. For the first time the resulting data of flies investigation (Diptera, Muscidae) in Samara Oblast territory are given. Up to the present time the revealed fauna of the houseflies is differed by the high taxonomic diversity and includes 75 species belonging to 26 genera. Among them 11 are the most frequent species Coenosia mollicula Fll., Coenosia testacea R.-D., Helina ciliatocosta Ztt., Helina moedlingensis Schnabl, Hydrotaea ignava Harris, Musca domestica L., Muscina levida Harris, Mydaea setifemur Ringdahl, Neomyia cornicina F., Pyrellia vivida R.-D. and Thricops semicinereus Wied. consisted of $15 \%$ of the all species regional muscid diversity. Main body of revealed muscid fauna in the region are represented by widely distributed and palaearctic species (by $45 \%$ in each group of distribution). Faunistic complex of muscid is characterized by richness of biotope clustering, habitat versatility of mostly species, and the most intensive flying period of the main species imagoes is noted in the summer period. It is supposed that compound of family in the generic level is revealed approximately of $79 \%$ and it is additionally expected 7 genera. Specific compound of the family is revealed approximately of $64 \%$ and it is additionally expected about 43 species of muscid in Samara Oblast fauna.

Keywords: house flies, Diptera, Muscidae, taxonomic diversity, fauna, distribution, biotope clustering, flying period of the main species imagoes, zoogeographical analysis, contemporary state of knowledge, list of the species, Samara Oblast.

УдК 574.42

\section{К ВОПРОСУ КЛАССИФИКАЦИИ ЭКОСИСТЕМ ЮГО-ВОСТОКА УКРАИНЫ}

(C) 2016

В.М. Остапко, доктор биологических наук, заместитель директора

Донеикий ботанический сад, Донеик (Донеикая Народная Республика)

О.М. Шевчук, доктор биологических наук, заведующий лабораторией ароматических и лекарственных растений Никитский ботанический сад - Национальный научный центр РАН, Республика Крым, пгт Никита (Россия)

С.А. Приходько, кандидат биологических наук, директор

Донеикий ботанический сад, Донецк (Донецкая Народная Республика)

Аннотащия. Рассматриваются современные подходы к классификации экосистем, как инструменту познания их разнообразия и связи с географическими и экологическими системообразующими факторами, а также для решения Самарский научный вестник. 2016. № 1 (14) 
практических задач по их охране и рациональному природопользованию. Предлагается классификация экосистем юго-востока Украины, основанная на доминантной классификации растительности. В основу классификации положено разделение экосистем по типу макроэкотопа (водораздельный, овражно-балочный, надпойменно-террасовый, пойменный) и эдафотопа (развитые чернозёмы, смытые чернозёмы на каменистых обнажениях песчаников, сланцев, гранитов, мергеля, известняка, мела, песчаные и луговые почвы). В основу разделения экосистем на одном и том же уровне каждого класса положены разные признаки: топические, физиономические, эдафические, динамические. Классификация построена по иерархическому принципу. Класс природных экосистем с доминированием фанерофитов включает экосистемы хвойных лесов и экосистемы лиственных лесов неморального типа, представленных в основном равнинно-водораздельными, пойменными и овражно-балочными (байрачными) дубравами. Класс природных злаково-травяных и кустарничковых экосистем представлен водно-болотными, луговыми и очень разнообразными степными экосистемами. Оба класса включают экосистемы разной степени увлажнения и смытости чернозёмов, а также приуроченности к эдафотопам, развитым на выходах различых горных пород. Класс антропогенных экосистем лишь намечен и нуждается в дальнейшей детализации. Приведены списки формаций и субформаций растительности, входящих в экосистемы низших ступеней иерархии.

Ключевые слова: классификация, экосистема, юго-восток Украины, растительность, формация, доминантная классификация растительности, лес, степь, луг, болото, водоём, солончак, чернозём, песок, мел, гранит, известняк, лёсс, сланец, песчаник, пойма, надпойменная терраса, овражно-балочная система.

Постановка проблемы в общем виде и ее связь с важными научными и практическими задачами. Для сохранения и восстановления природных экосистем, которые находяться под различным антропогенным прессом, первоочередным заданием является оценка состояния и прогнозирование их дальнейшего развития. Для выполнения этого задания необходимы детальные фитоценотические и популяционные исследования растительных сообществ с целью определения их как биомаркеров экосистем.

В кругу вопросов, которые требуют решения при исследовании процессов антропогенной динамики растительного покрова экосистем и индикации их состояния, ведущее место занимают вопросы классификации экосистем, поскольку она выступает основным методом их познания, упорядочивает информацию про объекты и обеспечивает определение понятий, находит форму оценки и решает вопросы соотношений между объектами, даёт способ измерения этих соотношений, служит методом получения новых знаний про объект, его свойства, выполняет разнообразные функции моделирования и прогнозирования [1]. Последнее сегодня имеет большое значение в связи с необходимостью сохранения биоразнообразия, установления биотической репрезентативности экосистем. Биологическое разнообразие определяется как вариабельность живых организмов во всех отношениях, в частности, среди других, с наземными, морскими и другими водними экосистемами и экосистемными комплексами, частью которых они являются, и включает разнообразие в пределах видов и между видами, а также разнообразие экосистем [2]. Таким образом, возникает необходимость в оценке разнообразия экосистем, которую невозможно осуществить без их классификации.

Анализ последних исследований и публикаичй, в которых рассматривались аспекты этой проблемы и на которых обосновывается автор; выделение неразрешенных раньше частей общей проблемы. Классификация является методологическим инструментом решения многих теоретических и практических проблем, а создание классификации является важным научным заданием [3]. Особенно актуальной является разработка классификации экосистем, которая давала бы возможность оценивать и сравнивать разнообразие экосистем разных территорий и выявлять их специфику. Однако, теоретические основы классификации экосистем, в отличие от классификации организмов и их соо- бществ, остаются недостаточно разработанными [4]. Классификацию EUNIS (European Nature Information System Habitat Classification) разрабатывали в 19962001 гг. Она построена по таким принципам: 1) обслуживается лёгким понятным языком; 2) использует чёткие, науучные, объективные признаки, которые имеют однозначную трактовку; 3) способна обеспечить создание систем в отношении разной экологической информации; 4) опирается на ранее созданные классификации; 5) имеет иерархическую структуру, которая отражает подчинённость экосистем; 6) одновременно является гибкою и устойчивою, что позволяет использовать новую информацию и усовершенствовать классификацию [3; 5].

Классификация EUNIS структурно не всегда строго выдержана, в разных типах экосистем на одном уровне иногда используют разные основы разделения, что вполне понятно учитывая значительную сложность объектов классификации и их эмерджентные свойства. Она основывается на флористической классификации растительности, её характерными чертами являются: иерархичность, использование признаков растительности (чёткие визуальные признаки благодаря физиономичности растительного покрова и чувствительные индикаторы условий среды), отражение всего разнообразия экосистем (природных, искусственных, наземных, морских и т.д.), наличие индексов и кодов для определения экосистем, пригодность к дополнению и усовершенствованию [6]. Эта классификация построена по типичному дедуктивному способу деления («сверху вниз»), однако в ней важное внимание уделено поиску наименьшей, элементарной единицы, за которую принимается habitat - экотоп, который определяется как «сообщество растений и животных как характерных элементов - биотической среды вместе с абиотическими факторами, которые взаимодействуют вместе в определённом масштабе» [7]. Таким образом, EUNIS это классификация экотопов, но понятие «экотоп» в ней используют как аналог понятия «экосистема». Собственно, ещё М. Хофман отмечал, что на площади одного экотопа находятся один биоценоз и одна экосистема [8]. Термин «экотоп» (habitat) в современном понимании является своеобразным компромиссом между функциональным наполнением понятия «экосистема» и хорологическим - «биогеоценоз».

Детальная классификация биотопов и их развёрнутая характеристика разработана чешскими ботаниками 
[9]. Оригинальную классификацию биотопов Германии (которые соответствуют экосистеме как абстрактной единице и биогеоценозу - как конкретной единице) приводит Х. Хауплер [10]. В Украине создана предварительная классификация экосистем, доведенная до четвертого иерархического уровня [11], которая основывается в основном на доминантной классификации растительности. Методику типизации и картирования биотопов на основе опыта немецких исследователей в Украине разрабатывал В.П. Ткачик [12]. Некоторые общие положения будущей классификации переувлажнённых экосистем Лесостепи Украины даёт Г.А. Чёрная [13].

Подходы к классификации экосистем в значительной мере определяются расхождениями в отношении определения объєкта классификации. С точки зрения общетеоретического значения и прикладного использования подобных классификаций наиболее удачным считается подход, который предусматривает классификацию экосистем по признакам их автотрофного блока, что в большинстве случаев играет ведущую роль в существовании экосистемы и опосредованно отражает свойства абиотической среды.

Теоретической основой наших исследований является понятие экосистемы как территориальной единицы, в основе которой лежит биотическая компонента, а абиотические факторы формируют среду её существования [14]. Биотическая компонента (биотоп - поверхность покрыта однотипной растительностью) является надёжным индикатором состояния экосистемы, что отражает её как потенциальный, так и реальный характер, степень развития и те изменения, которые происходят под влиянием антропогенного фактора.

Формирование изелей статьи (постановка задания). Целью статьи является разработка предварительной классификации экосистем юго-востока Украины, в которых существенную роль играет фитокомпонента из высших растений. Данная работа основывается на материалах полевых исследований, проведенных авторами в период с 1992 г. по 2013 г. на территории юговостока Украины (Донецкая и Луганская обл.) [15; 16] и на систематизированном фактическом материале геоботанических описаний и сведений из опубликованных источников $[17 ; 18 ; 19 ; 20]$.

Изложение основного материала исследования с полным обоснованием полученных научных результатов. Юго-восток Украины лежит в подзоне разнотравно-типчаково-ковыльных степей Приазовско-Черноморской подпровинции Причерноморской (Понтийской) степной провинции, Европейско-Азиатской степной области [21]. Характеризуется значительным геологическим и геоморфологическим разнообразием; принадлежит к континентальной степной области умеренных широт [22] - климат континентальный - и к умеренному (суббореальному) поясу, центральной лесостепной и степной области, зоне степи с чернозёмами обыкновенными, южными и мицеллярно-карбонатными, подзонам центральной степи. Для центральной степной области характерно преобладание обыкновенных чернозёмов. Узкой полосой вдоль берега Азовского моря залегают чернозёмы южноевропейской фации - мицеллярно-карбонатные [23].

При разработке классификации пользовались методологическими подходами, разработанными Я.П. Діду-
К вопросу классификации экосистем юго-востока Украины осор наименьшей основной единицы является ключевым для классификации экосистем. Такой единицею является экотоп «наименьшая основная реально существующая экосистема топологического (ландшафтного) уровня, для которой не существует основы деления на этом уровне. ... В геоботанике этому понятию соответствует фитоценоз...» [4].

В основу классификации экосистем юго-востока Украины положено представление о соответствии структуры и видового состава автотрофного блока экосистемы (фитоценоза) условиям местопроизрастания (экотопу). В основу классификаци положено разделение экосистем по типу макроэкотопа (водораздельный, овражно-балочный, надпойменно-террасовый, пойменный) [24] и эдафотопа (развитые чернозёмы, смытые чернозёмы на каменистых обнажениях песчаников, сланцев, гранитов, мергеля, известняка, мела, песчаные и луговые почвы). В основу разделения экосистем на одном и том же уровне каждого класса положены разные признаки: топические, физиономические, эдафические, динамические, что выплывает из эмерджентных свойств самого объекта классификации. Их использование обусловлено попыткою отразить наиважнейшие черты отличия или подобия объектов, которые рассматриваются. Классификация экосистем региона базируется на разработанной синтаксономической схеме природной растительности региона [15; 25].

Нами разработана классификация экосистем исследованного региона, в которой они сгруппированы в три класса: природные экосистемы с доминированием фанерофитов, которые включают экосистемы хвойных лесов и экосистемы лиственных лесов неморального типа, природные злаково-травяные и кустарничковые экосистемы (водно-болотные, луговые и степные экосистемы) и антропогенные экосистемы. Классификация построена по иерархическому принципу.

Классификация экосистем юго-востока Украины

Класс А. Природные экосистемы с доминированием фанерофитов (леса, редколесья, кустарники).

А.1. Экосистемы хвойных и лиственно-хвойных леcoв.

A.1.1. Надпойменно-террасовые и останцево-гривистые: леса формации Pineta cretaceae, дубравы формации Querceta roboris и березняки Betuleta pendulae с участием Pinus cretacea Kalenicz. ex Lypa на выходах мела на правом берегу р. Северский Донец.

А.1.2. Надпойменно-террасовые на песках: леса и лесные культуры из Pinus sylvestris L.

A.1.3. Надпойменно-террасовые на песках, приуроченные к дефляционным блюдцам: леса Betuleta pendulae, Betuleta borysthenicae, Pineto (sylvestris) Betuletum (pendulae), Alneto (glutinosae) - Betuletum (pendulae), Betuleto (pendulae) - Populetum (tremulae), Pineto (sylvestris) - Quercetum (roboris).

А.2. Экосистемы лиственных лесов неморального типа.

А.2.1. Дубравы неморального типа.

А.2.1.1. Равнинно-водораздельные.

А.2.1.1.1. На развитых чернозёмах.

А.2.1.1.1.1. Очень сухие: Querceta roboris, Fraxineta excelsioris, Acereto (campestris) - Quercetum (roboris) c доминированием в травяном ярусе Dactylis glomerata L., Galium aparine L. 
A.2.1.1.1.2. Сухие: Querceta roboris, Fraxineta excelsioris, Tilieto (cordatae) - Quercetum (roboris) anthriscosum (sylvestris), Acereto (campestris) - Quercetum (roboris) с доминированием в травяном ярусе Aegonychon purpureocaeruleum (L.) Holub, Melica picta K. Koch, Stellaria holostea L., Aristolochia clematitis L., Geum urbanum L., Galium aparine L.

А.2.1.2. Овражно-балочные.

А.2.1.2.1. На развитых чернозёмах.

A.2.1.2.1.1. Сухие: Querceta roboris, Fraxineta excelsioris, Acereto (campestris) - Quercetum (roboris) с доминированием в травяном ярусе Dactylis glomerata L., Poa nemoralis L., Aegonychon purpureocaeruleum (L.) Holub, Melica picta K. Koch, Geum urbanum L., Galium aparine L.

A.2.1.2.1.2. Влажные: Querceta roboris, Fraxineta excelsioris, Querceto (roboris) - Carpinetum (betuli), Fraxineto (excelsioris) - Carpinetum (betuli), Acereta campestris, Tilieto (cordatae) - Aceretum (campestris), Tilieto (cordatae) - Quercetum (roboris), Ulmeto (glabrae) - Fraxinetum (excelsioris) с доминированием в травяном яpyce Stellaria holostea L., Galium odoratum (L.) Scop.

A.2.1.2.1.3. Сырые: Querceta roboris, Fraxineta excelsioris, Acereta campestris, Acereto (platanoidis) Fraxineto (excelsioris) - Quercetum (roboris), Querceto (roboris) - Tilietum (cordatae) с доминированием в травяном ярусе Asarum europaeum L., Viola odorata L., Convallaria majalis L. Carex pilosa Scop., Carex hirta L., Vincetoxicum scandens Sommier \& Lévier, Carex rhizina Blytt ex Lindbl., Glechoma hederacea L.

A.2.1.2.1.4. Мокрые: Querceta roboris, Fraxineta excelsioris, Ulmeto (laevis) - Quercetum (roboris) с доминированием в травяном ярусе Aegopodium podagraria L., Urtica dioica L.

А.2.1.2.2. На смытых чернозёмах.

А.2.1.2.2.1. На каменистых обнажениях.

A.2.1.2.2.1.1. Сухие: Querceta roboris, Fraxineta excelsioris, Acereto (campestris) - Quercetum (roboris) c доминированием в травяном ярусе Dactylis glomerata L., Poa nemoralis L., Aegonychon purpureocaeruleum (L.) Holub, Melica picta K. Koch, Geum urbanum L.

A.2.1.2.2.1.2. Влажные: Querceta roboris, Fraxineta excelsioris, Acereta campestris, Tilieto (cordatae) Quercetum (roboris), Acereto (campestris) - Quercetum (roboris) с доминированием в травяном ярусе Stellaria holostea L., Galium odoratum (L.) Scop., Viola donetzkiensis Klokov.

A.2.1.2.2.1.3. Сырые: Querceta roboris, Fraxineta excelsioris, Fraxineto (excelsioris) - Tilietum (cordatae) c доминированием в травяном ярусе Asarum europaeum L., Viola odorata L., Convallaria majalis L.

A.2.1.2.2.1.4. Мокрые: Querceta roboris, Fraxineta excelsioris, с доминированием в травяном ярусе Aegopodium podagraria L., Urtica dioica L.

А.2.1.2.2.2. На выходах гранитов.

A.2.1.2.2.2.1. Сухие: Querceta roboris, Fraxineta excelsioris, Acereto (campestris) - Quercetum (roboris) c доминированием в травяном ярусе Poa nemoralis L., Melica picta K. Koch.

A.2.1.2.2.2.2. Влажные: Querceta roboris, Fraxineta excelsioris, Acereta campestris с доминированием в травяном ярусе Stellaria holostea L.

A.2.1.2.2.2.3. Сырые: Querceta roboris, Fraxineta excelsioris с доминированием в травяном ярусе Viola odorata $\mathrm{L}$.
A.2.1.2.2.2.4. Мокрые: Querceta roboris, Fraxineta excelsioris с доминированием в травяном ярусе Aegopodium podagraria L., Urtica dioica $\mathrm{L}$.

А.2.1.2.2.3. На выходах мела.

A.2.1.2.2.3.1. Сухие: Querceta roboris, Fraxineta excelsioris с доминированием в травяном ярусе Poa nemoralis L., Melica picta K. Koch., Geum urbanum L.

A.2.1.2.2.3.2. Влажные: Querceta roboris, Fraxineta excelsioris, Tilieto (cordatae) - Quercetum (roboris), Acereto (campestris) - Quercetum (roboris), Querceto (roboris) - Tilietum (cordatae) с доминированием в травяном яpyce Stellaria holostea L., Galium odoratum (L.) Scop.

A.2.1.2.2.3.3. Сырые: Querceta roboris, Fraxineta excelsioris, Acereto (platanoidis) - Fraxinetum (excelsioris), с доминированием в травяном ярусе Asarum europaeum L., Viola odorata L., Convallaria majalis L.

A.2.1.2.2.3.4. Мокрые: Querceta roboris, Fraxineta excelsioris с доминированием в травяном ярусе Aegopodium podagraria L., Urtica dioica L., Rubus caesius L.

А.2.1.3. Пойменные экосистемы.

А.2.1.3.1. На луговых почвах.

A.2.1.3.1.1. Сырые: Querceta roboris, Fraxineta excelsioris, Tilieto (cordatae) - Quercetum (roboris), Acereto (campestris) - Quercetum (roboris) с доминированием в травяном ярусе Stellaria holostea L., Asarum europaeum L., Viola odorata L., Convallaria majalis L., Vincetoxicum scandens Sommier \& Lévier, Carex rhizina Blytt ex Lindbl., Lysimachia nummularia L., Glechoma hederacea $\mathrm{L}$.

A.2.1.3.1.2. Мокрые: Querceta roboris, Fraxineta excelsioris, Ulmeto (laevis) - Quercetum (roboris) с доминированием в травяном ярусе Aegopodium podagraria L., Urtica dioica L., Rubus caesius L.

А.2.2. Мелколиственные леса.

A.2.2.1. Овражно-балочные: Populeta tremulae, Ulmeto (glabrae) - Populetum (tremulae), Saliceta fragilis.

A.2.2.2. Надпойменно-террасовые: Populeta tremulae, Betuleta pendulae.

A.2.2.3. Пойменные: Alneta glutinosae, Alneto (glutinosae) - Ulmetum (laevis), Ulmeta laevis, Saliceta albae, Saliceta fragilis, Populeta albae, Populeta nigrae, Querceto (roboris) - Ulmetum (laevis), Populeto (tremulae) - Ulmetum (laevis).

А.2.3. Заросли кустарников и кустарничков.

A.2.3.1. Ксерофитные: Cotineta coggigriae, Pruneta stepposae, Roseta corymbiferae, Spiraeeta hypericifoliae, Spiraeeta litwinowii, Ulmeta carpinifoliae, Caraganeta fruticis, Cotoneastereta melanocarpi, Chamaecytiseta ruthenicae, Amygdaleta nanae, Roseta subpygmaeae, Ceraseta fruticosae, Rhamneta catharticae, Crataegeta fallacinae.

A.2.3.2. Мезофитные: Acereta tatarici, Pruneta stepposae, Sambuceta nigrae, Ulmeta carpinifoliae, Swideta sanguineae.

A.2.3.3. Кустарниковые степи: Caraganeta fruticis, Amygdaleta nanae, Spiraeeta hypericifoliae, Calophaceta wolgaricae, Caraganeta scythicae.

Класс Б. Природные злаково-травяные и полукустарничковые экосистемы.

Б.1. Луговые экосистемы, которые формируются в условиях достаточного увлажнения.

Б.1.1. Овражно-балочные.

Б.1.1.1. Остепнённые луга на смытых чернозёмах: Bromopsieta inermis, Calamagrostieta epigeioris, Cariceta 
praecocis, Elytrigieta intermediae, Elytrigieta repentis, Medicagineta romanicae, Poeta angustifoliae, Festuceta rupicolae, Geranieta collini.

Б.1.2. Пойменные луга.

Б.1.2.1. Настоящие (злаковые и разнотравно-злаковые) луга на луговых почвах: Agrostieta giganteae, Agrostieta stoloniferae, Alopecureta pratensis, Artemisieta dracunculis, Bromopsieta inermis, Calamagrostieta epigeioris, Elytrigieta repentis, Festuceta arundinaceae, Festuceta pratensis, Koelerieta delavignei, Phleeta pratensis, Poeta angustifoliae, Poeta pratensis, Tanaceteta vulgaris, Trifolieta ambigui, Trifolieta pratensis.

Б.1.2.2. Болотистые луга на лугово-болотных и илисто-болотных почвах: Cariceta acutae, Cariceta atherodis, Cariceta distichae, Cariceta melanostachyae, Poeta palustris, Agrostieta stoloniferae, Beckmannieta eruciformis, Eleocharieta palustris, Equiseteta arvensis, Poeta palustris, Poeta trivialis, Agrostieta praticolae, Phalaroideta arundinaceae, Junceta compressi, Junceta gerardii.

Б.1.2.3. Засолённые луга: Artemisieta praticolae, Elytrigieta elongatae, Festuceta regelianae, Plantagineta cornuti, Plantagineta salsae, Poeta trivialis, Puccinellieta brachylepis, Tripolieta vulgaris, Holoscheneta vulgaris, Cariceta distans, Junceta gerardii, Rhaponticeta serratuloidis.

Б.2. Прибрежно-водные и водно-болотные экосистемы.

Б.2.1. Берега и литорали пресных водоёмов: Alismateta plantago-aquaticae, Bidenteta tripartitae, Butometa umbellati, Epilobieta parviflori, Glycerieta maximae, Mentheta longifoliae, Phragmiteta australis, Polygoneta amphibii, Ranunculeta repentis, Sagittarieta sagittifoliae, Sieta sisaroidei, Sparganieta erecti, Typheta latifoliae.

Б.2.2. Водоёмы с погружёнными и плавающими макрофитами: Utricularieta vulgaris, Batrachieta rionii, Ceratophylleta demersi, Lemneta minoris, Nuphareta luteae, Nymphaeeta albae, Potamogetoneta crispi, Potamogetoneta lucentis, Potamogetoneta pectinati, Potamogetoneta perfoliati, Ruppieta cirrhosae, Ruppieta maritimae, Salvinieta natantis, Stratioteta aloiditis, Zannichellieta majoris, Zostereta nanae.

Б.2.3. Мезотрофные болота: Alneto (glutinosae) sphagneta.

Б.2.4. Эвтрофные болота: Bolboschoeneta maritimi, Cariceta ripariae, Epilobieta hirsuti, Equiseteta sylvatici, Junceta compressi, Phragmiteta australis, Polygoneta persicariae, Polygoneta hydropiperis, Scirpeta lacustris, Scirpeta tabernaemontani, Typheta angustifoliae, Typheta latifoliae, Typheta laxmannii, Oenantheta aquaticae.

Б.3. Прибрежные морские экосистемы.

Б.3.1. Засолённые приморские луга: Aeluropeta littoralis, Agrostieta stoloniferae, Artemisieta boschniakianae, Bolboschoeneta maritimi, Limonieta meyeri, Elytrigieta elongatae, Glycyrrhizeta glabrae, Halimioneta pedunculatae, Junceta maritimi, Limonieta caspii, Puccinellieta brachylepis, Puccinellieta pseudoconvolutae, Triglochineta maritimae.

Б.3.2. Солончаки: Aeluropeta littoralis, Bassieta hirsutae, Frankenieta hirsutae, Salicornieta europaeae, Salsoleta sodae, Salsoleta tragici, Suaedeta prostratae, Tamariceta gracilis.

Б.4. Степные экосистемы (травяные и кустарниково-травяные экосистемы ксерофитного типа, которые формируются в условиях недостаточного увлажнения).
К вопросу классификации экосистем юго-востока Украины

Б.4.1. Разнотравно-типчаково-ковыльные степи.

Б.4.1.1. На водоразделах.

Б.4.1.1.1. На развитых чернозёмах: Amygdaleta nanae, Calophaceta wolgaricae, Caraganeta fruticis, Elytrigieta intermediae, Elytrigieta repentis, Elytrigieta trichophorae, Festuceta rupicolae, Festuceta valesiacae, Paeonieta tenuifoliae, Poeta angustifoliae, Poeta compressae, Spiraeeta hypericifoliae, Stipeta asperellae, Stipeta capillatae, Stipeta dazyphyllae, Stipeta lessingianae, Stipeta ucrainicae, Thymeta marschalliani, Vicieta tenuifoliae.

Б.4.1.1.2. На палеогеновых песках: Artemisieta marschallianae, Cariceta colchicae, Festuceta beckeri, Piloselleta officinari, Stipeta capillatae.

Б.4.1.2. Овражно-балочные степи на склонах.

Б.4.1.2.1. На смытых чернозёмах на глине: Amygdaleta nanae, Artemisieta ponticae, Astereta amelloidis, Bromopsieta inermis, Calophaceta wolgaricae, Caraganeta fruticis, Elytrigieta intermediae, Elytrigieta repentis, Elytrigieta trichophorae, Festuceta rupicolae, Festuceta valesiacae, Filipenduleta vulgaris, Fragarieta viridis, Inuleta germanicae, Koelerieta cristatae, Paeonieta tenuifoliae, Phlometa tuberosae, Poeta angustifoliae, Poeta compressae, Spiraeeta hypericifoliae, Stipeta asperellae, Stipeta capillatae, Stipeta dazyphyllae, Stipeta lessingianae, Stipeta rubentiformis, Stipeta stenophyllae, Stipeta ucrainicae, Thymeta marschalliani, Vicieta tenuifoliae.

5.4.1.2.2. На смытых чернозёмах на лёссах: Amygdaleta nanae, Astragaleta onobrychis, Bromopsieta ripariae, Caraganeta fruticis, Caraganeta scythicae, Crinitarieta villosae, Elytrigieta stipifoliae, Festuceta valesiacae, Inuleta germanicae, Koelerieta cristatae, Poeta compressae, Stipeta capillatae, Thymeta dimorphi.

Б.4.1.2.3. На смытых чернозёмах на гранитах: Achilleeta leptophyllae, Amygdaleta nanae, Artemisieta marschallianae, Bromopsieta ripariae, Caraganeta fruticis, Crinitarieta villosae, Erodieta becketowii, Euphorbieta cretophilae, Festuceta valesiacae, Koelerieta cristatae, Pimpinelleta titanophilae, Scrophularieta donetzicae, Spiraeeta hypericifoliae, Stipeta capillatae, Stipeta dazyphyllae, Stipeta graniticolae, Thymeta granitici, Thymeta pseudogranitici.

Б.4.1.2.4. На смытых чернозёмах на известняках: Achilleeta nobilis, Artemisieta marschallianae, Astereta amelloidis, Botriochloeta ischaemi, Bromopsieta ripariae, Caraganeta fruticis, Caraganeta scythicae, Crinitarieta villosae, Elytrigieta stipifoliae, Festuceta valesiacae, Genisteta scythicae, Jurineeta brachycephalae, Koelerieta cristatae, Lineta czerniaevii, Pimpinelleta titanophilae, Salvieta nutantis, Stipeta capillatae, Stipeta dazyphyllae, Thymeta calcarei, Thymeta dimorphi.

Б.4.1.2.5. На смытых чернозёмах на мелах: Artemisieta hololeucae, Artemisieta nutantis, Artemisieta tanaiticae, Astereta bessarabici, Astragaleta albicaulis, Caraganeta fruticis, Cephalarieta uralensis, Crinitarieta villosae, Elytrigieta cretaceae, Elytrigieta stipifoliae, Euphorbieta cretophilae, Festuceta cretaceae, Festuceta valesiacae, Filipenduleta vulgaris, Helianthemeta cretophili, Hyssopeta cretacei, Jurineeta brachycephalae, Lineta ucrainicae, Onosmateta tanaiticae, Pimpinelleta titanophilae, Poeta compressae, Salvieta nutantis, Scrophularieta cretaceae, Stipeta capillatae, Stipeta joannis, Teucrieta polii, Thymeta cretacei, Thymeta didukhii, Thymeta kondratjukii.

Б.4.1.2.6. На песчаниках и сланцах: Achilleeta leptophyllae, Amygdaleta nanae, Achilleeta nobilis, Artemisieta 
marschallianae, Astereta amelloidis, Bromopsieta ripariae, Caraganeta fruticis, Crinitarieta villosae, Elytrigieta stipifoliae, Festuceta valesiacae, Koelerieta cristatae, Lineta czerniaevii, Scrophularieta donetzicae, Spiraeeta hypericifoliae, Stipeta capillatae, Stipeta dazyphyllae, Stipeta lessingianae, Thymeta dimorphi.

Б.4.1.2.7. На палеогеновых песках: Artemisieta marschallianae, Cariceta colchicae, Chamaecytiseta ruthenicae, Festuceta beckeri, Inuleta hirtae, Koelerieta cristatae, Piloselleta officinari, Stipeta capillatae, Thymeta pallasiani.

Б.4.1.3. Надпойменно-террасовые степи.

Б.4.1.3.1. На голоценовых песках: Agropyreta pectinati, Artemisieta marschallianae, Artemisieta tscherniaevianae, Cariceta colchicae, Chamaecytiseta ruthenicae, Festuceta beckeri, Helichryseta arenarii, Koelerieta sabuletori, Piloselleta officinari, Stipeta borysthenicae, Stipeta capillatae, Stipeta joannis, Thymeta pallasiani.

Б.4.1.3.2. На смытых чернозёмах на мелах: Caraganeta fruticis, Crinitarieta villosae, Elytrigieta stipifoliae, Festuceta valesiacae, Filipenduleta vulgaris, Jurineeta brachycephalae, Koelerieta cristatae, Lineta ucrainicae, Pimpinelleta titanophilae, Stipeta capillatae, Stipeta joannis, Stipeta lessingianae, Thymeta cretacei.

Б.4.1.3.3. На смытых чернозёмах на лёссах: Amygdaleta nanae, Artemisieta marschallianae, Astragaleta onobrychis, Caraganeta fruticis, Crinitarieta villosae, Festuceta valesiacae, Koelerieta cristatae, Stipeta capillatae, Stipeta lessingianae, Thymeta dimorphi.

Класс В. Экосистемы антропогенного происхождения.

В.1. Агроэкосистемы.

В.1.1. Сегетального типа с ежегодной обработкой почвы.

В.1.2. Одно-двух-трёхкомпонентные посевы кормовых трав.

В.1.3. Многокомпонентные кормовые агрофитоценозы.

В.2. Экосистемы искусственных древесно-кустарниковых насаждений.

В.2.1. Лесные культуры хвойных и лиственных пород.

В.2.2. Защитные древесно-кустарниковые насаждения (полезащитные, придорожные, противоэрозионные лесополосы и т.п.).

В.2.3. Парки, скверы, бульвары, ботанические сады, дендропарки и другие древесно-кустарниковые насаждения урбоэкосистем.

В.2.4. Сады и виноградники, питомники зелёного строительства.

В.3. Фиторекультивированные антропогенные экотопы (отвалы, насыпи, дамбы, шламоотстойники и т.п.).

Выводы исследования и перспективы дальнейтих изысканий данного направления. Таким образом, разработана классификация экосистем юго-востока Украины, в которой они выделяются по степени нарушенности (природные и антропогенные), по жизненной форме фитокомпонента (экосистемы с доминированием фанерофитов и злаково-травяные экосистемы), по приуроченности к определённому типу макроэкотопа и эдафотопа, по уровню увлажнённости. Принцип построения этой классификации позволяет её дальнейшее совершенствование и дополнение на любой ступени иерархии.

\section{СПИСОК ЛИТЕРАТУРЫ:}

1. Дидух Я.П., Шеляг-Сосонко Ю.Р. Сущность классификации // Продромус растит. Украины. Киев: Наук. думка, 1991. С. 12-23.

2. Convention on biological diversity, $1992.31 \mathrm{p}$.

3. Davies C.E., Moss D. EUNIS Habitat Classification. Final Report to the European Topic Centre on Nature Conservation. European Environment Agency. 1999. 256 p.

4. Дідух Я.П. Методологічні підходи до створення класифікації екосистем // Укр. ботан. журн. 2004. 61, № 1. C. 12-23.

5. Davies C.E., Moss D. EUNIS Habitat Classification. Final Report. European Topic Centre on Nature Conservation. Paris. 1997.99 p.

6. Davies C.E., Moss D. EUNIS Habitat Classification. Database and Parrte Frame for a European Classification. European Topic Centre on Nature Conservation. Paris. 1997. $15 \mathrm{p}$.

7. Davies C.E., Moss D., Hill M.O. EUNIS Habitat Classification Revised. European Topic Centre on Nature Conservation. Paris, 2004.

8. Василевич В.И. Очерки теоретической фитоценологии. Л.: Наука, 1983. 247 с.

9. Chytry M., Kucera Tomás, Kocí Martin. Katalog biotope Ceské republiky. Praha: Agentura ochrany přírody a krajiny ČR, 2001. 304 s.

10. Haeupler D. Biotope Deutschlands // Schrift. F. Vegetationsk. 2002. H. 38. S. 247-272.

11. Дідух Я.П., Шеляг-Сосонко Ю.Р. Класифікація екосистем - імператив національної екомережі України // Укр. ботан. журн. 2001. 58, № 4. С. 393-403.

12. Ткачик В.П. Методика виявлення, картування i типізації біотопів. Львів, 1997. 34 с.

13. Чёрная Г.А. Классификация переувлажненных екосистем Лесостепи Украины // V Bсе рос. Конф. По водным растениям «Гидроботаника 2000»: Тез. докл. Борок, 2000. С. 233-234.

14. Дідух Я.П. Теоретичні підходи до створення класифікації екосистем // Укр. фітоценот. збірник. Серія С. Фітоекологія. Вип. 23. Фітосоціоцентр, 2005. C. $3-15$.

15. Остапко В.М. Продромус естественной растительности юго-востока Украины. Донецк, 1995. 142 с.

16. Глухов О.3., Остапко В.М., Шевчук О.М., Суслова О.П., Приходько С.А. Класифікаційна схема екосистем в межах південного сходу України // Відновлення порушених природних екосистем: Матеріали Третьої міжнародної наукової конференції (м. Донецьк, 7-9 жовтня 2008 р.). Донецьк, 2008. С. 23-29.

17. Рослинність УРСР. Природні луки. К.: Наук. думка, 1968. 256 с.

18. Рослинність УРСР. Степи, кам'янисті відслонення, піски. К.: Наук. думка, 1973. 428 с.

19. Лавренко Е.М. Степи СССР // Растительность СССР: В 5 т. М., Л.: Изд-во АН СССР, 1940. Т. 2. С. 1266.

20. Лавренко Е.М., Карамышева 3.В., Никулина Р.И. Степи Евразии. Л.: Наука, 1991. 146 с.

21. Лавренко Е.М. Эдафические варианты степной растительности Причерноморской степной провинции // Растительность Европейской части СССР. Л.: Наука, 1980. C. 249-254. 
22. Природа Украинской ССР. Климат / Отв. ред. М.И.Щербань. Киев: Наукова думка, 1984. 232 с.

23. Національний атлас України / НАН України, Інститут географії, Державна служба геодезії, картографії та кадастру; голов. ред. Національного атласу України Л.Г. Руденко; голова ред. кол. Б.С. Патон. К.: ДНВП «Картографія», 2007. 435 с.

\section{TO THE PROBLEM OF CLASSIFICATION OF ECOSYSTEMS OF SOUTH EAST UKRAINE} (C) 2016

V.M. Ostapko, doctor of biological sciences, deputy director Donetsk Botanical Garden, Donetsk (Donetsk People's Republic)

O.M. Shevchuk, doctor of biological sciences, head of the Laboratory of Aromatic and Medicinal Plants Nikita Botanical Garden - National Research Center of Russian Academy of Sciences, Republic of Crimea, s. Nikita (Russia)

S.A. Prikhodko, candidate of biological sciences, director Donetsk Botanical Garden, Donetsk (Donetsk People's Republic)

Abstract. This work addresses modern approaches to the classification of ecosystems as a tool for understanding of their diversity and relation to geographical and environmental systemic factors, as well as for solving practical problems of conservation and rational management. A classification of ecosystems of south east Ukraine is given based on the dominant vegetation classification. The basis of classification is the division of ecosystems according to the type of macroecotope (watershed, gully, above flood-plain terrace, floodplain) and edaphotope (developed black soil, washed away black soil on rocky sandstone outcrops, shale, granite, marl, limestone, chalk, sandy and meadow soils). The basis for the division of ecosystems of the same level of each class is based on different features: topical, physionomic, edaphic, dynamic. Classification is based on hierarchical principle. The class of natural ecosystems with dominance of phanerophytes includes ecosystems of coniferous forests and deciduous forest ecosystems of nemoral type, represented mainly by lowlandwatershed, gully (ravine) oakeries. The class of natural grass and shrub ecosystems is represented by wetland, grassland and extremely diverse steppe ecosystems. Both classes include ecosystems with different moistening, soil erosion and confinement to edafotopes, developed at the outcrops of different rock types. Class of anthropogenic ecosystems is outlined in general and needs more detailed study. We compiled a lists of formations and subformations of vegetation, belonging to of the lower hierarchy level ecosystems.

Keywords: classification, ecosystem, south east of Ukraine, vegetation, formation, dominant classification of vegetation, forest, steppe, meadow, swamp, pond, salt marsh, black soil, sand, chalk, granite, limestone, loess, shale, sandstone, floodplain, floodplain terrace, ravine and beam system.

УДК 592

\section{ВРЕМЕННЫЕ БЮДЖЕТЫ ДНЕВНОЙ АКТИВНОСТИ ЖУКОВ-ЛИСТОЕДОВ (COLEOPTERA, CHRYSOMELIDAE) HA РАЗНЫХ ЭТАПАХ ИХ ГЕНЕРАЦИОННОГО ЦИКЛА}

(C) 2016

С.И. Павлов, кандидат биологических наук, доцент кафедры биологии, экологии и методики обучения Самарский государственный социально-педагогический университет, Самара (Россия)

Аннотация. В течение 1974-2010 гг. в природных и лабораторных условиях в Самарской области изучались нативные (естественные) двигательные реакции активных жизненных фаз (имаго и личинок) 4-х видов жуковлистоедов (Coleoptera, Chrysomelidae), имеющих 1-годичную генерацию. В зависимости от доминирующей на каждом этапе онтогенеза «биологической программы», типа двигательной активности (набора конкретных движений) и временных бюджетов реализации этих движений, весь генерационный (репродуктивный) цикл был разбит на 4 этапа - функциональных блока поведенческих реакций. К ним были отнесены - прекопуляционный период (время созревания имаго), этап копуляции (спаривания взрослых жуков), этап овуляции (созревания и откладки яиц) и этап эмбриогенеза (отрождения и развития личинок). Рассмотрена динамика продолжительности светлого периода суток (когда листоеды деятельны) в течение всего генерационного периода. Вычислена продолжительность «полезного» времени светлого периода дня (для данной широты местности), т.е. астрономическая долгота дня за вычетом длительности утренних и вечерних сумерек (когда относительно холодно, выпадает роса и насекомые неактивны), именно тот период, когда листоеды наиболее подвижны. Подсчитаны реальные временные бюджеты двигательной активности в течение светлого времени суток на разных этапах генерационного цикла. Зарегистрированы и изучены основные типы двигательных реакций листоедов. Установлено, что таких реакций - 13 , общих для всех этапов -5 , специфических -8 .

Ключевые слова: жуки-листоеды, имаго и личинки, генерационный цикл, 4 этапа репродуктивного процесса: прекопуляционный период, этап копуляции, этап овуляции, этап эмбриогенеза, временные бюджеты активности в течение светлого времени суток, основные типы двигательных реакций. 